\section{Cross-European Technology Assessment: Visions for the European TA Landscape}

\author{
by Walter PeissI, ITA Vienna, and Marianne \\ Barland, Norwegian Board of Technology
}

The whole of Europe is getting more closely connected and, with the rapid technological development, there seems to be a need for establishing networks and knowledge bases in a cross-European manner. This can be advantageous for both the national and regional levels of policy making as well as for the European one. This paper discusses the past, present and future of cross-European work going on in the field of parliamentary technology assessment (PTA). ${ }^{1}$ The main questions to be dealt with will be: What did we learn from past cross-European projects? What is the additional value provided by cross-European TA? And how can cross-European TA be structurally established in the long term? To answer them, we analyse the existing framework conditions for cross-European projects, compare ten cases of previous cross-European projects and draw some lessons. In the final part we present conclusions and recommendations for fostering cross-European cooperation within the TA community.

\section{Technology Assessment in Europe}

In the 1970s, the OECD, the European Commission (EC) and individual states took initiatives to introduce technology assessment in Europe. Following this, offices for parliamentary technology assessment (PTA) were established in several European countries and regions. In 1990 - following an initiative of Lord Kennet, at that time chair of the advisory board of the U.K. parliamentary TA institution (POST), the European Parliamentary Technology Assessment (EPTA) network was established. Founding member institutions were POST, the Parliamentary Office of the Evaluation of Scientific and Technological Choices - FR (OPECST), the Office of Technology Assessment at the German Bundestag (TAB), the Rathenau Institute, the Danish Board of Technology (DBT), and the Science and Technology Options Assessment at the European parliament (STOA) (Wennrich 1999). Today, EPTA has 14 members and three associate members (http:// www.eptanetwork.org). It aims at strengthening the links between parliamentary offices for TA throughout Europe, and establishing TA as an integral method advising parliaments in decision-making. The approaches to TA applied by the member institutions vary widely, both in their organizational structure and working methods. ${ }^{2}$

Although a number of joint projects have been conducted in the framework of EPTA or funded by the European Commission (see below), one cannot speak of regular cross-European cooperation in TA up to now. The whole of Europe is getting more closely connected, the EU is growing, and the rapid technological developments have implications that go beyond national borders. In this respect, there seems to be a need for establishing result-oriented European cooperation and networks in the field of TA, so that technological innovation can be considered in a global perspective, taking into account both national and European realities.

Based on our personal experience and the analysis of several cross-European projects, this paper discusses three topics: What is the added value of cross-European TA work? Who are the addressees and target groups of cross-European projects? And what are the possible tensions between national/regional TA structures and the ambition to "act European"? Within the framework of the PACITA (Parliaments and Civil Society in Technology Assessment) project two workshops have been organized where these questions have been discussed between PACITA partners and other TA actors in Europe ${ }^{3}$. In addition, partners in the PACITA project have compiled several case descriptions of cross-European projects conducted previously, which have been compared with regards to process, financing, mode of cooperation etc., in order to find the strengths and weaknesses of cross-European projects (Barland et al. 2012). The endeavour to achieve closer cooperation between European TA institutions lies at the core of the PACITA initiative. The project has set an aim to foster the 
European scope of technology assessment and create a vision for cross-European TA in 2020.

\section{Cross-European TA: A Definition and a Short History}

In the context of this paper we define cross-European TA as TA (projects) done by a group of TA institutions across borders. It implies a common objective and cooperation but not necessarily the use of the same methods. Cross-European TA is not necessarily pan-European TA in the sense that the whole of Europe (28+) is covered in terms of membership, whether in the consortium or with regard to the results and impact of the project. Pan-European TA on the one hand aims at a collective Europe, whereas cross-European TA cherishes the diversity of approaches and cultural contexts in order to reach added value for all addressees and involved actors.

The history of cross-European TA projects more or less starts (at least within the EPTA context) with the EUROpTA project (1998-1999), which was partly financed by the Targeted socio-economic research TSER programme of the EC in FP4. This first "joint project" already showed some characteristics of cross-European projects: It was the wish of some members of EPTA to work together on methodological issues of participatory technology assessment (pTA). EUROpTA evaluated pTA and its contribution to European policy. It scrutinised the theoretical and conceptual frameworks that underlie both theoretical discussions and practical initiatives of pTA. It clearly showed the differences in Europe and the potential and limitations of pTA at that time in different socio-political contexts. It created added value for the understanding of the different ways pTA could be utilised in different countries and issued guidelines for practice in pTA based on this analysis. From a procedural point of view, cross-European cooperation in this project clearly revealed that in interdisciplinary and intercultural research settings it takes time to find a common understanding and common ground for further work, which then can be highly productive and creative. As time is costly, this leads directly to the next lesson learned: (enough) resources and flexibility are needed. Already this first "joint project" showed in a paradigmatic way some of the key issues we found in our analysis of later projects. The next attempt was the TAMI project (2002-2003), which again was a methodological project that tried to identify "best practices" for different problem contexts in order to develop guidance for the selection of TA methods. TAMI again was to a great part driven by EPTA members and was financed by the EC under the STRATA programme in FP5.

These two projects may be seen as early forerunners. The list below shows the ten further projects with TA units as partners that were analysed during the PACITA project (which in itself is a cross-European project).

- ICT and Privacy in Europe (EPTA, 20042006)

- Meeting of Minds - European Citizens' Deliberation on Brain Science (FP6, 20042006)

- Energy transition in Europe (EPTA, 20062007)

- PRISE - Privacy enhancing shaping of security research and technology - a participatory approach to develop acceptable and accepted principles for European security industries and policies (EC/PASR, 20062008)

- Genetically modified plants and foods: Challenges and future issues in Europe (EPTA, 2006-2009)

- Study on Human Enhancement (STOA/EP, Start: 2008-2009)

- World Wide Views on Global Warming (mixed sources, 2008-2009)

- Citizen visions on science, technology \& innovation (CIVISTI)(FP7/SSH, 2008-2011)

- Technology Options in Urban Transport: Changing paradigms and promising innovation pathways (STOA/EP, 2010-2011)

- Nano Safety - Risk Governance of Manufactured Nanoparticles (STOA/EP, 2010-2011)

This list ${ }^{4}$ shows a broad range of different settings and characteristics of cross-European TA projects. Six out of the ten projects have been 
carried out by consortia with TA units only, and one project had a scope beyond Europe.

With regard to funding/initiators, the first group are so-called "EPTA projects". These projects are based on the "Joint EPTA Project Framework", where three or more members can initiate a project, which is open for participation by other EPTA members. They may be classical research projects like "ICT and Privacy in Europe" or rather short but comprehensive overview projects like "Energy transition in Europe". They are based on the EPTA members' own budget. At least for the first research-like projects, this turned out to be one of the weak points. Missing resources and no "external" client - not to be mixed up with addressee - tend to diminish the priority of such projects in the member organisations. This implies the danger of lower commitment by partners and therefore greater efforts at coordination. The later projects, focusing on collecting national policy overviews on a given topic, seemed therefore to be a more suitable format for EPTA projects. These overview projects use a common framework to be filled in by EPTA partners, which can be done in relatively short time. These projects do have a concrete aim and addressee. They are used to complement discussions of parliamentarians and TA practitioners at the EPTA conferences, which are held annually in the capital city of the respective EPTA presidency's country. EPTA reports on five such joint projects from 2004 until 2014 are now available (http://www. eptanetwork.org). Further issues are synthetic biology and technology-related productivity in Europe and the USA.

The second group of projects are based on funding by the European Parliament (EP), represented by STOA (European Parliament Science and Technology Options Assessment), which itself is part of the EPTA network. From this list of cases STOA commissioned three cross-European TA projects. Since October 2005, the European Technology Assessment Group (ETAG) ${ }^{5}$ has served as one of the contractors to STOA. Projects of this kind are clearly defined policy advice studies with a specific addressee (the EP) and are conducted within a rather tight framework.
The EC research framework programmes finance the third - important - type of cross-European TA projects. These projects react to calls of the EC, whereas the EPTA projects only rely on the assessment of the EPTA members as to whether an issue is relevant or not. So far the former have been conducted by small consortia involving a majority of TA institutions (like PRISE) or brought together a lot of different actors (like "Meeting of Minds"). Being bound to calls from the framework programmes restricts the flexibility with regard to themes to a certain extent. Nevertheless some TA institutions have cooperated in such FP projects in recent years; examples beyond those four listed above are: $\operatorname{DESSI}^{5}$ (2011-2013), SurPRISE ${ }^{6}$ (2012-2015) and PACITA $^{7}$ (2011-2015).

The ten cases also show the broad range of methods employed in cross-European projects. All include desk research to a different extent, and six out of eleven used participatory elements in their work. The duration was 8 to 40 months and almost all projects at least tried to address policy makers on the European level in addition to those on the national and sometimes regional level. Most of them concluded with reports and more or less concrete recommendations - sometimes more openly referred to as "challenges" or "policy options".

One of the problems that has been articulated is a loss of accuracy due to translation problems occurring in multi-national settings, which intensified as soon as laypeople participate. Multiple translations back and forth between national languages and the working language (English) of the consortia are very critical aspects and have to be given high attention.

Besides the categorisation based on financing we can observe a twofold development in the European scene. On the one hand, many of the cross-European projects rely on and cherish the diversity of approaches used in different countries and TA institutions. On the other hand, there are attempts to apply the same methodology in all the participating countries. The reasoning behind this is (i) to compare results from different cultural settings and (ii) to be cost efficient by designing the projects only once. This second approach was applied by the PACITA 
project, which conducted three case studies in some of the participating countries by applying the same method in all of them.

From the small list of projects above and the formal categorisation alone, we can see a high diversity of procedures. Based on this we will now investigate further what this means for the future of cross-European TA.

\section{Is There Added Value in Doing Cross- European Projects?}

Although the emerging technologies debated in different countries are more or less the same, the contexts and timing of discussions as well as the shaping of technologies will differ nationally. Thus, cross-European TA can contribute to setting the agenda and providing policy support at the European level and at the same time informing the national science and technology discourses. All European countries (whether EU members or not) relate to European regulation in some areas. These areas of regulation are interesting subjects for cross-European TA, which could create a common platform between partners for assessing the national impact and implications as well as challenges to the national implementation of regulations.

PTA institutions have their mandate mainly focused on the national and regional sphere. Some have the explicit task to "watch trends in science and technology" (Ganzevles/van Est 2012) (both national and international), but for none is participation in international projects defined as a formal task. Identifying and understanding the added value in cross-European projects may help to open up and stimulate more cooperation while at the same time justifying international cooperation at the national level.

For TA institutions involved in cross-European co-operation, such participation itself can produce added value. The cooperation with other institutions provides a setting for institutional learning and an exchange of experience. How one approaches a topic, which method one chooses, and how a project is framed is highly contextual. Input from and discussions with other practitioners are mutually benefi- cial. It broadens the perspectives applied to the problems at stake and can shed light on overlooked sides of an issue. The networks can also strengthen capacity, both of the institutions and the PTA community as a whole: for PTA units with limited resources, the contact with other units enhances their portfolio and broadens their field of expertise and range of methods. This was the leading idea for the joint TA projects carried out within the framework of PACITA, which was very much appreciated as a means of integrating TA in their portfolio by PACITA partners from countries with no existing TA infrastructures so far. Within the PACITA framework different kinds of partners have conducted three exemplary projects using three different methods. The projects on public health genomics, the future of ageing, and sustainable consumption should encourage TA activities in several European countries, including in those that do not yet have an established TA institution. PACITA has also created the TA Portal, which is an open resource for knowledge sharing and learning about TA.

More than ever, technological change is being driven by and is itself a driving force of globalisation. Therefore, it is logical that the assessment of new technological developments also adapts to the international or European level through networks and cooperation. European science policy has made a move from "science in Europe" to "European science" (Nedeva/Stampfer 2012). The focus has moved from the coordination of national projects, to the development of a more integrated, pan-European science base. Signs for this shift may be seen in the establishment of the European Research Area (ERA) and the European Research Council (ERC). Given this shift, it is getting even more important for TA to be present on a European level.

\section{Whom to Address?}

One of the main characteristics of many European TA units with a central role in their national context is their strong connection to the parliament. This is institutionally provided for by organizing the unit inside parliament (the parlia- 
mentary committee or parliamentary office models) (STOA 2012) or by identifying parliament as the main addressee in the mission statement of a TA institution (independent institute model) (Ganzevles/Nentwich 2014). Nevertheless, many of the PTA units additionally communicate their results to a larger audience consisting of different target groups including the scientific community, ministries or other governmental offices and the general public.

When the PTA activities move up to the European level, it becomes more difficult to identify addressees and potential target groups. If a contractual relationship is established with a policy making institution (the European Parliament in the case of ETAG or the Commission in the case of EU-funded projects), there is a TA client, and thus an addressee, with identifiable expectations and needs. However in the case of bottom up activities of cross-European TA initiated by EPTA, the addressee in the first instance would be the interested European public. Brussels serves as an important policy arena, with many important target groups within the EU represented. While in a national context there is a defined public sphere, there is no easily addressable "European public".

Given this situation and knowing about the importance of a clear addressee as a prerequisite for having an impact, there is a clear need for cross-European TA to actively explore ways of identifying and establishing contacts with addressees and target groups at the European level. First of all, a thorough dissemination strategy is needed in cross-European projects. Every project has to identify its own public, which most likely will be quite different from project to project. Second, it could be productive to have a more systematic view of addressees and target groups when working at the European level than at the national/regional level. If the goal of PTA is to provide input for knowledge-based decision-making, it might help to broaden the definition of who decision-makers really are. In a national context, the parliament and government stand out as the main decision-makers. In the European context, the European Commission and the European Parliament play important roles. Yet many others (e.g. lobbyists, NGOs, and the media) also take part in decisions and hold power in important discussions.

\section{What Does It Mean to "Go European"?}

For many PTA units, doing national projects and participating in European projects creates tension. Easing this tension might be one of the factors that can lower the threshold for doing cross-European TA. This tension is rooted in the fact that the mission of PTA institutions is mainly national in focus. Thus, participating in European projects might take both focus and resources away from their working programs. Therefore, providing sufficient additional resources from European funds for cross-European activities can be one important factor in lowering the threshold for national bodies to engage in European activities. The increasing participation in EU-funded projects also supports this notion. Institutions easily see the added value of joining a consortium when there are special funds available for working at the European level.

However, a strong argument can be made that cross-European TA may be stronger if there is structural financing for European cooperation which is not limited to individual projects. The opportunity to really establish cross-European TA as a field, and having the finances to the keep up the work, might make the European sphere more enticing. Long-term presence and more structural financing by a European programme or body would be an incentive for more cross-European work.

Being part of a European network is in itself of great value to many institutions. It gives input and updates both on topics of interest and developments in the field of TA. Networks like EPTA strengthen the position of TA in Europe and the rest of the world. Through EPTA and initiatives like PACITA, countries and institutions that seek to establish PTA structures can get access to a larger group of PTA units and to possibilities for mutual learning. Nevertheless the barriers described above have hindered a more vital development of cross-European TA. 


\section{Conclusions: The Need for Structural Financing and Organisational Representation of Cross-European TA}

There are many arguments that prove the added value of doing cross-European work in the field of TA. Some of them are: mutual organisational learning; broadening the portfolio of members; being responsive; acting cost-efficiently; and being present at the relevant political level. But there are also some barriers: the difficulty to find the right addressee; the difficulty in making an impact on the European level; and the tension that can arise between the national/regional structures and resources when participating in cross-European work. The most striking seems to be the absence of a European actor and of structural funds for TA. When aiming at a broader range of decision-making processes in $\mathrm{Eu}-$ rope, the European Parliament (and STOA) are important actors in the field. To foster cross-European collaboration we need a broader range of settings for collaboration and being open for additional addressees besides the EP. Establishing stronger TA across borders depends on several factors, some of which are structural, external factors, and some are factors that the institutions involved can influence themselves.

External factors: The biggest external challenge is financing. There is a need for more structural form of financing of cross-European activities. Participation beyond single projects would help to establishing TA as a stronger source for advising European decision-making and would encourage institutions to commit themselves for a longer term. In order to acquire these funds, we envisage a European TA stakeholder, who would be present "in Europe" and whose tasks would be to (i) lobby for funds in the long run and (ii) to help European TA institutions to get funds from existing programmes for the envisaged cross-European TA in the short term. Whether this European TA stakeholder could be a stronger EPTA or a new kind of TA association is an open question. Anyhow, there is a need for an organisational push for cross-European TA.

Internal factors: Successful projects are probably the best encouragement for setting up new projects. To achieve this and to adapt to the European level, there are certain internal factors the institutions should consider on the project level. Being used to working in an interdisciplinary field, applying a wide range of methods, and involving different groups of people, TA institutions are well prepared for cooperation with different institutions and across borders. However, one area that is particularly complex at the European level is the communication and dissemination of the projects' results. To have an impact, the addressee and potential target groups must be defined explicitly for each project. This takes time and effort, but will prove useful both during the project and when communicating the message in the end.

For many TA units and their funders, the best use of their resources has been on the national or regional level, where their main tasks and addressees are located. To overcome the tension that might occur between the national/regional and the European levels, there are several things to consider. First, if a more structural form of financing would be established, cross-European work would not take away resources dedicated to the national or regional level. Second, the exchange of knowledge that occurs in cooperation might actually save resources. If an institution has done work in a specific area, others should not be afraid to use the experience and knowledge already produced in this specific field. To participate in European networks and common projects can provide institutions with valuable knowledge.

Partners in the PACITA project have set up working groups that will explore the opportunities for establishing a European TA association. Taking a more inclusive and diverse approach is something that might help create a stronger TA community in Europe. Including institutions beyond parliamentary TA (like in the German context) will broaden the field and create a stronger basis for having an impact on decision-making on the European as well as the national/regional levels.

Having an impact on decision-making and knowledge production in Europe should be the overall goal of European TA organisations. This demands more activity by them and a strong presence in the European arena. 


\section{Notes}

1) This paper is based on work done for the EU funded project PACITA (Parliaments and Civil Society in Technology Assessment).

2) For a more thorough description of the different TA institutions, see Ganzevles/van Est 2012 and Ganzevles et al. 2014, also: van Est et al. in this volume.

3) Including partners from EPTA and STOA that are not active partners in PACITA.

4) Detailed case descriptions can be found in the annex of the PACITA project deliverable D2.4 "Making cross European TA" at: http://www.pacitaproject.eu/wp-content/uploads/2014/11/PACITA-D-2-4_Cross-European-TA_FINAL_incl-annex.pdf (download 15.12.14).

5) ETAG is led by ITAS and consists of the following partners: DBT, Rathenau Institute, Fraunhofer ISI, FCRI, ITA, VITO, Technology Centre ASCR and Responsible Technology SAS (http://www.itas. kit.edu/english/etag.php).

6) DESSI: Decision Support System for Security Decisions. The DESSI project provides a process and a decision support system to end users of security investments. The system gives insight into the pros and cons of specific security investments. It contributes to a transparent and participatory decision-making that accounts for context and multi-dimensionality of society (http://securitydecisions.org/)

7) SurPRISE: Surveillance, Privacy and Security: A large scale participatory assessment of criteria and factors determining acceptability and acceptance of security technologies in Europe (http:// surprise-project.eu/).

8) PACITA: Parliaments and Civil Society in Technology Assessment: Broadening the knowledge base in policy making. PACITA is a four-year EU financed project under FP7 aimed at increasing the capacity and enhancing the institutional foundation for knowledge-based policy-making on issues involving science, technology and innovation, mainly based upon the diversity of practices in Parliamentary Technology Assessment (PTA) (http://www.pacitaproject.eu/).

\section{References}

Barland, M.; Peissl, W.; Bütschi, D. et al., 2012: Making Cross-European TA. PACITA, Deliverable 2.4

Ganzevles, J.; van Est, R.; Nentwich, M., 2014: Embracing Variety: Introducing the Inclusive Modelling of
(Parliamentary) Technology Assessment. In: Journal of Responsible Innovation 1/3 (2014), pp. 292-313

Ganzevles, J.; van Est, R. (eds.), 2012: TA Practices in Europe. PACITA, Deliverable 2.2; http://www.pacitaproject.eu/wp-content/uploads/2013/01/TA-Practices-in-Europe-final.pdf (download 11.12.14)

Nevada, M.; Stampfer, M., 2012: From "Science in Europe" to "European Science". In: SCIENCE 336 (2012), pp. 982-983

STOA - Science and Technology Options Assessment, 2012: Technology Across Borders. Exploring the Perspectives for Pan-European Parliamentary Technology Assessment; http://www.europarl.europa.eu/RegData/etudes/etudes/join/2011/482684/ IPOL-JOIN_ET\%282011\%29482684_EN.pdf (download 11.12.14)

Vig, N.J.; Paschen, H., 1999: Parliaments and Technology. The Development of Technology Assessment in Europe. New York

Wennrich, Chr., 1999: European Parliamentary Technology Assessment Network (EPTA). In: Bröchler, S.; Simonis, G.; Sundermann, K. (eds.): Handbuch der Technikfolgenabschätzung. Berlin, pp. 535-537

\section{Contact}

Dr. Walter Peissl

Institute of Technology Assessment

of the Austrian Academy of Sciences

Strohgasse 45/5, 1030 Vienna, Austria

Email:wpeiss1@oeaw.ac.at 